\title{
Motor responses of the human alimentary tract to near-maximal infusions of pentagastrin
}

\author{
J. J. MISIEWICZ, D. J. HOLDSTOCK, AND SHEILA L. WALLER \\ From the Medical Research Council Gastroenterology Research Unit, \\ Central Middlesex Hospital, London
}

EDITORIAL COMMENT Near maximal infusions of pentagastrin were found to have no consistent effect upon motility except in the gastric antrum. The results suggest that gastrin is not directly concerned in the mediation of the gastro-colic reflex.

The motor effects of gastrin on the alimentary tract have not been studied extensively in man although responses to single intravenous injections of gastrin II and its synthetic analogue pentagastrin (I.C.I. 50,123, Peptavlon) have been reported (Smith and Hogg, 1966; Logan and Connell, 1966). It is not yet clear what is the role of the antral hormone in the control of motility in general and of the gastro-colic reflex in particular. Endogenous gastrin is probably released continuously during meals and a circulating factor capable of stimulating acid production persists in the bloodstream for some two hours following the ingestion of food (Johnston, Buchan, and Giles, 1965).

We have therefore investigated the effects of continuous intravenous infusion of pentagastrin in doses resulting in near-maximal output of acid on the motor activity of the stomach and the colon, and have compared the findings with other studies, in which intravenous histamine or intramuscular ametazole (Histalog) replaced the pentagastrin as the secretory stimulus. The effect of single intravenous injections of pentagastrin on the colon was also studied for comparison with previous work.

\section{PATIENTS AND METHODS}

Observations were made on 49 patients referred either for gastric secretory studies or for tests of colonic motility. The additional procedures involved in the present investigation were carefully explained, and the patients were free to refuse them if they so wished; they all agreed to the test. Simultaneous measurements of acid output and motor activity of the stomach and colon were originally made in 39 patients, but the results in seven were excluded, because of a change in position of the gastric tube during the test. Of the 32 patients in whom the test was satisfactory, 17 received pentagastrin, seven intravenous histamine, and eight intramuscular ametazole. In the 10 remaining patients, the effect of single intravenous injections of pentagastrin on the motor activity of the sigmoid and the rectum was measured. Brief clinical details of the patients studied are set out in Table I.

COLLECTION AND ANALYSIS OF GASTRIC JUICE Gastric juice was aspirated continuously by a combination of pump and syringe suction and the acid titrated with $\mathrm{N} / 10 \mathrm{NaOH}$ to $\mathrm{pH} 7.4$ on an automatic burette.

MEASUREMENT OF INTRALUMINAL PRESSURES AND ANALYSIS OF RECORDS Pressures in the gastric antrum and fundus

TABLE I

Stimulus

\begin{tabular}{lll}
$\begin{array}{l}\text { No. of } \\
\text { Patients }\end{array}$ & \multicolumn{2}{c}{ Diagnosis } \\
\cline { 2 - 3 } & $\begin{array}{l}\text { Duodenal } \\
\text { or Gastric } \\
\text { Ulcer }\end{array}$ & $\begin{array}{l}\text { Britable } \\
\text { Syndrome }\end{array}$
\end{tabular}

Studies Available for Analysis

\begin{tabular}{llll}
\hline Fundus Antrum & $\begin{array}{l}\text { Right } \\
\text { Colon }\end{array}$ & $\begin{array}{l}\text { Sigmoid } \\
\text { Colon }\end{array}$ & Rectum
\end{tabular}

Ulcer Syndrome

\footnotetext{
Intravenous infusion, pentagastrin

Intravenous infusion, histamine

Intramuscular, ametazole

Single intravenous injections, pentagastrin
}

$\begin{array}{rrrrrrrrr}17 & 9 & 4 & 4 & 8 & 10 & 7 & 11 & 10 \\ 7 & 3 & 0 & 4 & 6 & 7 & - & 5 & 5 \\ 8 & 6 & 0 & 2 & 7 & 8 & - & - & - \\ 10 & 2 & 5 & 3 & - & - & - & 19 & 19\end{array}$


were measured with two open-ended polyethylene tubes of $0.9 \mathrm{~mm}$. bore, which were fastened to the radiopaque gastric suction tube with the recording tips $10 \mathrm{~cm}$. apart. The pressure tubes were perfused with distilled water from a motor-driven syringe at the rate of $10 \mathrm{ml} . / \mathrm{hr}$., to prevent blockage by gastric mucus. The distal pressure tip was placed in the antrum under fluoroscopic control.

Motor activity of the ascending colon was telemetered with a pressure sensitive radiocapsule (Rowlands and Wolff, 1960), ingested by the patient the previous night. The telemetered signal was picked up on an omnidirectional aerial (Connell, McCall, Misiewicz, and Rowlands, 1963) placed near the right iliac fossa, and connected to a radio pill receiver. The location of the radiocapsule was deduced from fluoroscopy and inspection of the pressure records, there being characteristic differences in the frequency and amplitude of pressure waves recorded from the small and large intestine.

Pressures in the sigmoid and rectum were measured with two $10 \times 7 \mathrm{~mm}$. air-filled rubber balloons mounted on narrow tubes, which were placed through a sigmoidoscope so that the balloons lay at approximately 10 and $20 \mathrm{~cm}$. from the anal margin, the sigmoidoscope then being withdrawn. Twenty minutes were allowed to elapse between sigmoidoscopy and the start of recording.

The location of the gastric suction and pressure tubes and of the radio telemetering capsule was checked by fluoroscopy before and after each study. The open-ended tubes, balloons, and telemetering capsules were calibrated in terms of centimetres of water pressure, and motor activity of the various parts of the gut was recorded simultaneously on a multichannel penwriter.

Records were analysed by measuring the height $(\mathrm{H})$ and duration (D) of each pressure wave and calculating a motility index (M.I.) from the formula M.I. $=\frac{\Sigma(\mathrm{H} \times \mathrm{D})}{\mathrm{T}}$, where $\mathbf{T}=$ duration in minutes of the experimental period under analysis. Records were excluded from analysis if the configuration of the pressure waves indicated that a recording tip had moved to another part of the gut, e.g., from the antrum into the duodenum.

DESIGN OF STUDY AND CALCULATION OF RESUlTS All the studies were made on fasting patients. The tests involving simultaneous measurements of gastric secretion and gastrointestinal motor activity consisted of six consecutive half-hour observation periods. During the first hour (control periods I and II) dextrose saline was infused as a placebo and basal levels of gastric secretion and of gastrointestinal motor activity were measured. During the next two half-hour periods (periods III and IV), pentagastrin was given intravenously at the dose level of $0.01 \mu \mathrm{g} . / \mathrm{kg}$./ min. This dose was raised to $0.1 \mu \mathrm{g} . / \mathrm{kg}$. $/ \mathrm{min}$. for the following half-hour (period V). Gastric juice was aspirated continuously throughout periods I to V. In the last halfhour observation period (period VI) pentagastrin was again given at the lower dose of $0.01 \mu \mathrm{g} . / \mathrm{kg} . / \mathrm{min}$., but gastric suction was stopped to allow acid to enter the duodenum, while the measurements of motor activity were continued. When intravenous infusion of histamine (0.04 mg./kg./hr.) was substituted for the pentagastrin,
$50 \mathrm{mg}$. of mepyramine maleate was injected intramuscularly at the end of period I. In other tests, $1.5 \mathrm{mg}$. or $2.0 \mathrm{mg} . / \mathrm{kg}$. of ametazole was injected intramuscularly at the end of the second control period (period II). Recording of results and timing of observation periods was the same as in the pentagastrin studies. Acid was collected and pressure records were made and analysed over corresponding $10 \mathrm{~min}$. periods in order to detect any transient effects, but for presentation the results in each half-hour have been pooled.

The tests with single injections of pentagastrin consisted of five 30-min. observation periods. After the first halfhour, during which basal colonic motor activity was measured, control injections of saline were given before the second and fourth observation periods, while pentagastrin in doses ranging from 0.1 to $0.9 \mu \mathrm{g} . / \mathrm{kg}$. was injected before the third and fifth periods. All the intravenous injections of saline or of the analogue were made over $3 \mathrm{~min}$. immediately preceding the observation periods.

Each patient acted as his own control. In the combined secretory and motor activity studies, Student's t test was used to detect significant differences between observation periods, the following comparisons being made: control period I was compared with control period II, period II was compared with periods III, IV, and V, and period V was compared with period VI. Similar procedures were used to assess the effects of single injections of pentagastrin.

The number of pressure studies available for analysis at the various sites is shown in Table I. In the combined secretion/motor activity tests, there were no significant changes in the M.I. between periods I and II at any of the sites studied, indicating adequate control of the observations.

\section{RESULTS}

EFFECTS ON GASTRIC SECRETION Figure 1 summarizes the gastric secretory response of the 32 patients studied. In all of the 17 patients who were given an infusion of pentagastrin at the dose of $0.01 \mu \mathrm{g} . / \mathrm{kg} . /$ min., there was a prompt stimulation of gastric secretion, the increase occurring within 10 minutes of the start of the infusion in 10 patients. The output of acid rose markedly during the first half-hour with a further rise during the second half-hour of the infusion at the lower dose (Fig. 1a, periods III and IV). The tenfold increase in the dose of pentagastrin (Fig. 1a, period V) was followed by a further rise of acid output in nine of the 17 patients, but the mean increase was only $1.48 \mathrm{mEq} / 30 \mathrm{~min}$., and the difference from the level of secretion in the previous half-hour was not significant $(P>0.3)$. Increase in acid output after infusion of histamine and after ametazole was of the same order as after pentagastrin, when allowance is made for the small number of subjects in the three groups and a higher proportion of patients with duodenal ulcer in the ametazole group (Figs. $1 \mathrm{~b}$ and $\mathrm{c}$ ). 
FIG. 1. Mean output of acid in response to, a, pentagastrin (I.C.I. 50,123) infusion; b, ametazole (histalog); $\mathrm{c}$, histamine infusion. Horizontal bars represent S.E. of the mean.

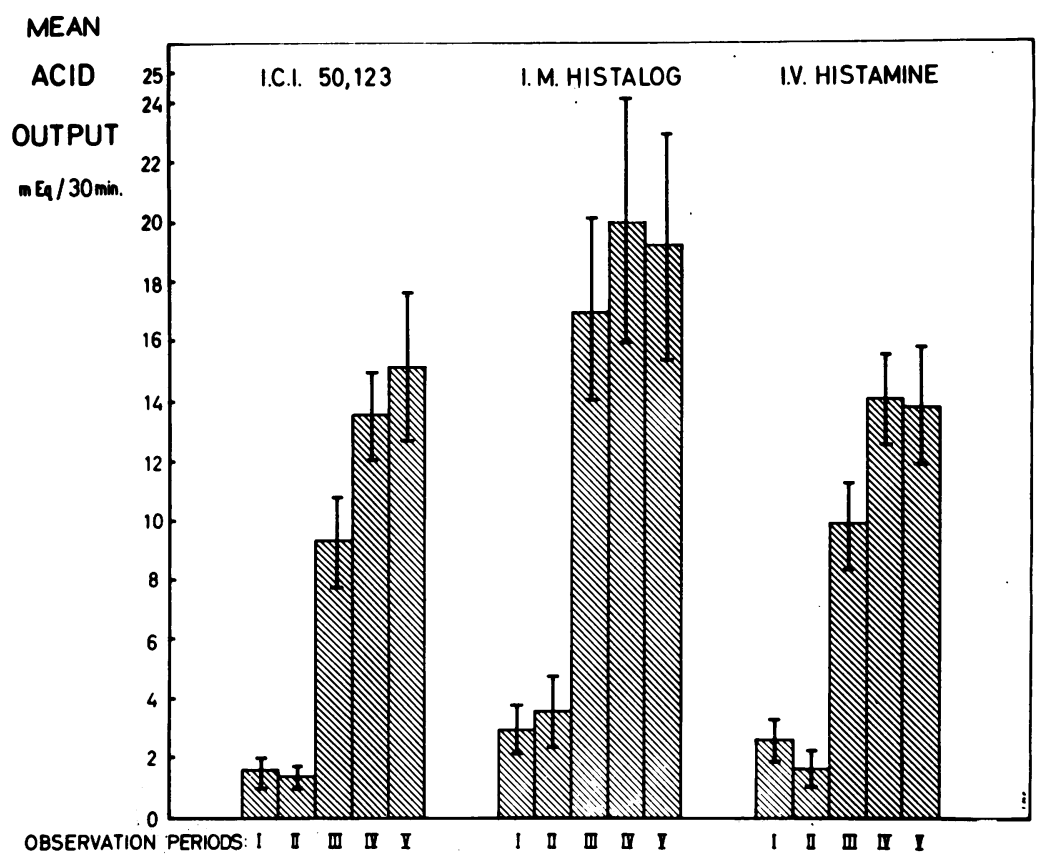

MOTOR ACTIVITY OF GASTRIC ANTRUM AND FUNDUS There was an increase in antral motor activity in response to pentagastrin at the dose of $0.01 \mu \mathrm{g} . / \mathrm{kg} . /$ $\mathrm{min}$. in eight of the 10 patients studied. The response of one patient is shown in Figure 2. Analysis of the antral pressure records showed that intravenous pentagastrin given at $0.01 \mu \mathrm{g} . / \mathrm{kg} . / \mathrm{min}$. (Fig. 3, periods III and IV) was accompanied by a rise in the antral motor activity which differed significantly from both the control periods $(P<0.05)$. Raising the dose to $0 \cdot 1 \mu \mathrm{g} . / \mathrm{kg}$. $/ \mathrm{hr}$. produced a further increase in antral M.I. in three of nine patients, but the
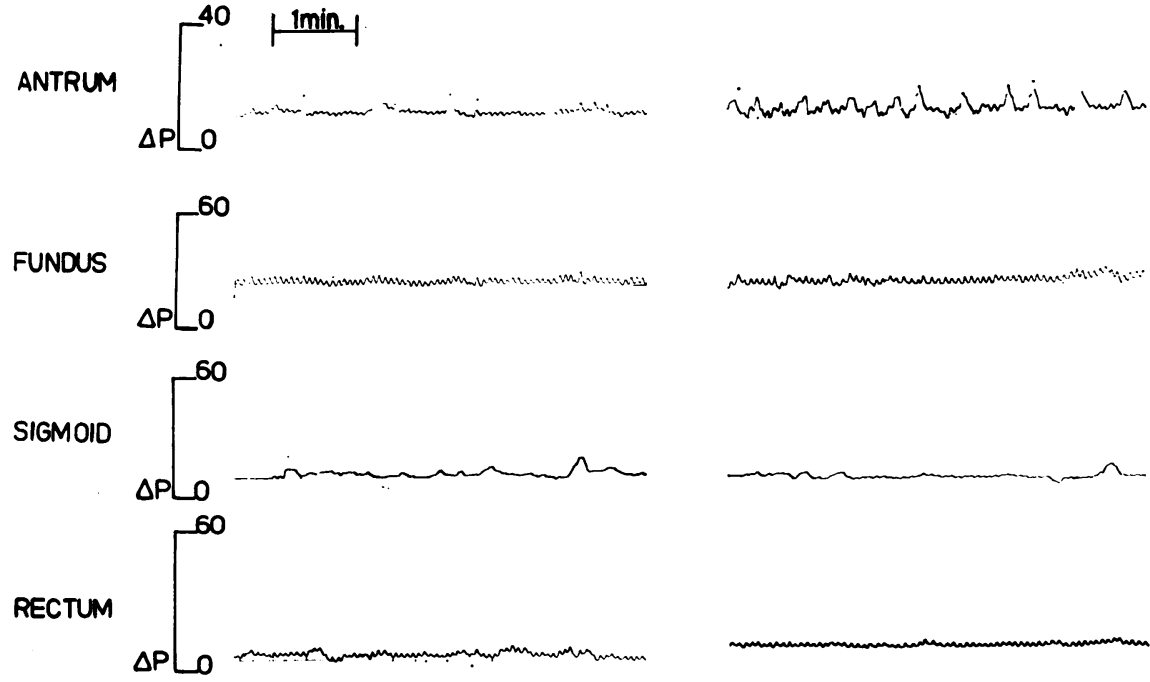

FIG. 2. Simultaneous intraluminal pressures in the stomach and the left colon before and during the infusion of pentagastrin. Pressure in $\mathrm{cm}$. of water. 


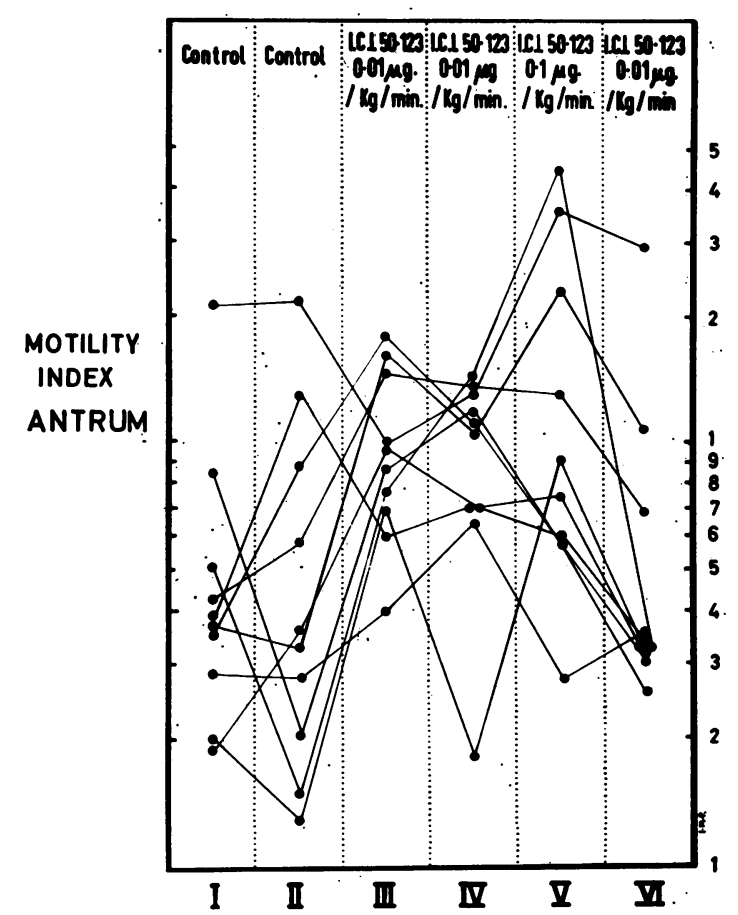

FIG. 3. Antral motility index (M.I.) of individual patients receiving pentagastrin. Log M.I. on the vertical axis; observation periods on the horizontal axis.

significance of difference from control periods was not increased $(P<0.05)$. The increase in antral M.I. correlated well with increase in the output of acid ( $\mathrm{n}=49, \mathrm{r}=0.57, \mathrm{P}<0.001)$. In contrast, analysis of the fundal pressure records revealed no significant change in pressure activity during infusion of pentagastrin combined with gastric suction, when compared with controls.

When gastric suction was stopped while the infusion of pentagastrin was continued (Fig. 3, period VI), antral motor activity was markedly inhibited in eight of the 10 patients $(P<0.02)$. Motor activity of the fundus also fell during period VI in seven of the eight patients studied $(P<0.05)$.

In contrast, neither intravenous histamine nor ametazole caused a significant increase in the motor activity of the fundus or antrum in any of the observation periods during gastric suction. In period VI when gastric suction was discontinued, the motor activity of antrum and fundus diminished in both groups.

MOTOR ACTIVITY OF RIGHT COLON, SIGMOID, AND RECTUM The motor activity of the right colon, sigmoid, and rectum did not differ significantly from controls during the administration of pentagastrin at either dose level. The radiotelemetering capsule moved distally in one test only, its position remaining unchanged in the other six. Allowing the acid to enter the duodenum during continued administration of pentagastrin (period VI) had no effect on the motor activity of the right colon or of the rectum. However, sigmoid motor activity increased during that period (Fig. 4) in seven of 11 patients when compared with period V $(\mathrm{P}<0.05)$.

Sigmoid and rectal motor activity was also measured in five of the patients who received intravenous histamine (Table I). There was no consistent change in colonic M.I. during gastric suction (periods III, IV, and V). In the four patients in whom results were available for period VI sigmoid motor activity increased in three but the increase was not significant $(\mathrm{P}>0 \cdot 3)$.

EFFECT OF SINGLE INJECTIONS OF PENTAGASTRIN ON MOTOR ACTIVITY OF SIGMOID AND RECTUM Nineteen tests were carried out on 10 patients, seven of which were made with $0 \cdot 1 \mu \mathrm{g}$., two with $0 \cdot 2 \mu \mathrm{g}$., seven with $0.3 \mu \mathrm{g}$., two with $0.4 \mu \mathrm{g}$., and one with $0.9 \mu \mathrm{g}$. $/ \mathrm{kg}$. of pentagastrin injected over three minutes. All the

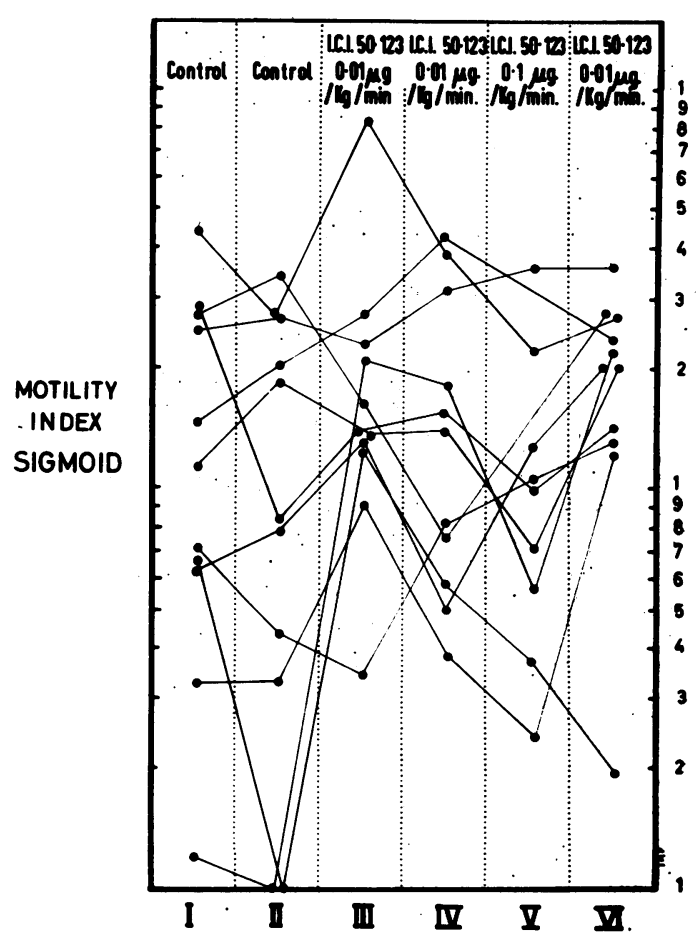

FIG. 4. Sigmoid motility index (M.I.) of individual patients receiving pentagastrin. Log. M.I. on the vertical axis; observation periods on the horizontal axis. 
patients except one were tested with two different doses of the analogue. No significant difference from control or placebo periods was observed in the $30 \mathrm{~min}$. following the injection of $0 \cdot 1$ or $0 \cdot 3 \mu \mathrm{g}$. $/ \mathrm{kg}$. of pentagastrin. Similar analysis made of $10 \mathrm{~min}$. periods before and after each injection also gave negative results. There was no consistent effect on the motor activity of the colon after the other doses of pentagastrin, but the number of tests was too small for statistical analysis.

SIDE EFFECTS No side effects were observed from the intravenous infusion of pentagastrin at $0.01 \mu \mathrm{g} . / \mathrm{kg}$. $/$ min. Four patients complained of nausea when the higher dose was given; in two the dose had to be reduced while in the others the nausea subsided spontaneously. Nine of the 19 tests made with single injections of pentagastrin were accompanied by side effects which occurred over the whole range of dosage used, the frequency and severity increasing with higher doses. The symptoms generally resembled those reported previously by Logan and Connell (1966).

\section{DISCUSSION}

After the isolation and synthesis of gastrin (Gregory and Tracy, 1961, 1964; Anderson, Barton, Gregory, Hardy, Kenner, MacLeod, Preston, Sheppard, and Morley, 1964) it was found that the physiological properties of the hormones were determined by the C-terminal tetrapeptide sequence (Morley, Tracy, and Gregory, 1965). The synthetic analogue used in this study has a t-butyloxycarbonyl- $\beta$-alanine added to the functional tetrapeptide residue. The physiological actions of pentagastrin closely resemble those of the hormone, but are not identical. The analogue is 11 times less potent on a molar basis as a stimulant of gastric secretion (Barrett, 1966) and side effects can occur from intravenous administration (Wormsley, Mahoney, and $\mathrm{Ng}, 1966$; Logan and Connell, 1966; present results). Although in vitro experiments on human tissue show a close similarity of action between gastrin and the analogue (Bennett, Misiewicz, and Waller, 1967), the extrapolation of present results to gastrin itself should be made with caution.

Intravenous infusion of pentagastrin at the rate of $0.01 \mu \mathrm{g} . / \mathrm{kg} . / \mathrm{min}$. resulted in a level of gastric secretion which was not significantly increased by raising the dose tenfold, suggesting that a near-maximal secretory response to pentagastrin was achieved. This finding agrees with data reported by Wormsley et al. (1966). Histamine and ametazole were given in doses known to produce maximal gastric secretory responses (Lawrie, Smith, and Forrest, 1964;
Laudano and Roncorini, 1965; Wormsley and Grossman, 1965).

The pentagastrin stimulated both antral motor activity and the secretion of acid. Histamine and ametazole increased acid secretion while antral motor activity remained unchanged. This suggests that stimulation of the parietal cell by histamine and histalog takes place without the endogenous release of gastrin.

The main stimulus to the release of endogenous gastrin is probably the ingestion of food. Johnston et al. (1965) showed that a humoral factor which enhanced the secretion of acid persisted in the peripheral blood for about two hours following a meal. Using base-excess in the arterial blood as a measure of gastric secretion, Rune (1966) has demonstrated that the secretory response to a meal continues for about two hours and is of the same order as, if not greater than, the response to a maximal dose of intravenous histamine. It is likely, therefore, that both the rate and duration of acid secretion in our patients approximated to that caused by a meal.

Under these conditions, the present results suggest that the direct motor effects of pentagastrin may be confined to the stomach. It is unlikely that the increase in antral motor activity was caused by distension with excess secretion not removed by suction, since no increase in antral M.I. was apparent during the peak response to intravenous histamine or ametazole. It is perhaps surprising that no significant stimulation of the gastric fundus was observed. The proximal pressure tip was located only just below the cardia, and in retrospect, it would have been better to record pressures from the body of the stomach. The proximal tip slipped into the cardiac sphincter on several occasions and it was our impression that this occurred soon after the start of the pentagastrin infusion. This could mean that the 'tone' of the stomach was increased by pentagastrin causing a diminution in gastric volume.

Further supporting evidence that the direct motor effects of pentagastrin may be confined to the stomach comes from in vitro studies on isolated human alimentary muscle, in which both gastrin and its analogue selectively stimulated strips from the stomach, while having no effect on those from the small intestine and little effect on those from the colon (Bennett et al., 1967).

When gastric suction was stopped, antral and fundic motor activity were rapidly inhibited despite continued administration of pentagastrin and it is reasonable to infer that this effect was caused by the escape of gastric secretion into the duodenum. Inhibition of gastric motor activity by acidification of the duodenum is well known (Schapiro and Woodward, 1955) but the mechanism is uncertain. Chole- 
cystokinin and pancreozymin may be involved in the mediation of the motor inhibitory mechanism (Johnson, Brown, and Magee, 1966) but another, as yet unidentified, humoral agent is probably responsible for the inhibition of acid secretion (Johnston and Duthie, 1966). The motor inhibitory effects are of physiological importance, as gastric emptying may be controlled by the activity of the antral pump. Our findings on antral motor activity are in keeping with the observation of Johnston and Duthie (1965) that acid secretion stimulated by gastrin II was inhibited by perfusing the duodenum with hydrochloric acid. This lends further weight to the argument of these authors that duodenal continuity should be preserved in operations for duodenal ulcer.

Comparatively few studies of the effect of gastrin on intestinal motility have been made and none have incluced the effects of constant infusion. In the dog, intravenous gastrin II, 10 to $50 \mu \mathrm{g}$., caused contraction followed by a relaxation of the small intestine (Gregory and Tracy, 1964). In a preliminary study Smith and Hogg (1966) described widespread stimulation of alimentary motility following single intravenous injections of large doses of gastrin II. Logan and Connell (1966) reported that intravenous injections of pentagastrin in doses ranging from 0.25 to $0.5 \mu \mathrm{g} . / \mathrm{kg}$. given over three minutes sometimes stimulated rectal and sigmoid activity in two of three subjects, although the time interval and magnitude of response could not be related to the dose and inhibition, rather than stimulation, of the sigmoid occurred at times. We have been unable to find any consistent increase in the motor activity of the sigmoid and rectum either during prolonged infusions combined with gastric suction, or after single intravenous injections of pentagastrin.

Assuming that the physiological properties of pentagastrin resemble those of the antral hormone, the results of this study do not suggest that gastrin is directly concerned in the mediation of the gastrocolic reflex; activity of the right and left colon did not alter during the infusion of pentagastrin and the telemetering capsule was not propelled distally during the study. Gastrin may, however, have an indirect role to play in the reflex. In this context the tendency for the motor activity of the sigmoid to increase during period VI in the pentagastrin and histamine group is interesting, although the data are not conclusive. One interpretation is that a factor released by the entry of acid into the duodenum caused an increase in the motor activity of the colon. Thus any increase in colonic motor activity following single injections of gastrin or pentagastrin could be due to such a mechanism. It is not impossible for the same factor to have a differential effect on various parts of the gut, and such a response has already been shown with 5-hydroxytryptamine (Misiewicz, Waller, and Eisner, 1966).

The present results are consistent with the hypothesis that diarrhoea in those patients with the Zollinger-Ellison syndrome who have hypersecretion of acid is caused by low intestinal $\mathrm{pH}$ (Singleton, Kern, and Waddell, 1965; Donaldson, Von Eigen, and Dwight, 1957; Summerskill, 1959), since we have been unable to show a direct motor effect on the colon in vivo and on the small intestine in vitro (Bennett et al., 1967). It may be, however, that very high blood levels of gastrin are present in this syndrome, and the possibility that direct motor effects of the hormone occur at higher concentrations cannot be excluded.

\section{SUMMARY}

Motor responses of the gastrointestinal tract were measured in patients during intravenous infusion of a synthetic analogue of gastrin (I.C.I. 50,123, pentagastrin) given in doses sufficient to raise gastric acid secretion to near-maximal levels. The motor activity of the antrum was stimulated, but the right and left colon were unresponsive. In contrast, maximal doses of histamine and ametazole had no motor effect on the gut. Single injections of pentagastrin did not stimulate the distal colon. The results suggest that direct motor effects of the pentagastrin may be confined to the stomach.

We thank Dr. F. Avery Jones and Dr. T. D. Kellock for permission to study patients under their care. We are grateful to Dr. J. D. Fitzgerald of I.C.I. for the generous gift of pentagastrin (Peptavlon). Mrs. Vivien Binks provided invaluable technical assistance.

\section{REFERENCES}

Anderson, J. C., Barton, M. A., Gregory, R. A., Hardy, P. M., Kenner, G. W., MacLeod, J. K., Preston, J., Sheppard, R. C., and Morley, J. S. (1964). Synthesis of gastrin. Nature (Lond.), 204, 933-934.

Barrett, A. M. (1966). Specific stimulation of gastric acid secretion by a pentapeptide derivative of gastrin. J. Pharm. Pharmacol., 18, 633-639.

Bennett, A., Misiewicz, J. J., and Waller, S. L. (1967). Analysis of the motor effects of gastrin and pentagastrin on the human alimentary tract in vitro. Gut, 8, 470-474.

Connell, A. M., McCall, J., Misiewicz, J. J., and Rowlands, E. N. (1963). Observations on the clinical use of radiopills. Brit. med. J., 2, 771-774.

Donaldson, R. N., Jr., Von Eigen, P. R., and Dwight, R. W. (1957). Gastric hypersecretion, peptic ulceration and islet-cell tumor of the pancreas (the Zollinger-Ellison syndrome). New Engl. J. Med., 257, 965-970.

Gregory, R. A., and Tracy, H. J. (1961). The preparation and properties of gastrin. J. Physiol. (Lond.), 156, 523-543. (1964). The constitution and properties of two gastrins extracted from hog antral mucosa. Gut, 5, 103-114. 
Johnston, D., Buchan, R., and Giles, G. R. (1965). Autotransfusion in man. Lancet, 2, 271-272.

- and Duthie, H. L. (1965). Inhibition of gastrin secretion by the human stomach. Ibid., 2, 1032-1036.

(1966). Inhibition of histamine-stimulated gastric secretion by acid in the duodenum in man. Gut, 7, 58-68.

Laudano, O. M., and Roncorini, E. C. (1965). Determination of the dose of histalog that provokes maximal gastric secretory response. Gastroenterology, 49, 372-374.

Lawrie, J. H., Smith, G. M. R., and Forrest, A. P. M. (1964). The histamine-infusion test. Lancet, 2, 270-273.

Logan, C. J. H., and Connell, A. M. (1966). The effect of a synthetic gastrin-like pentapeptide (I.C.I. 50,123) on intestinal motility in man. Ibid., 1, 996-999.

Misiewicz, J. J., Waller, S. L., and Eisner, M. (1966). Motor responses of human gastrointestinal tract to 5-hydroxytryptamine in vivo and in vitro. Gut, 7, 208-216.

Morley, J. S., Tracy, H. J., and Gregory, R. A. (1965). Structurefunction relationships in the active C-terminal tetrapeptide sequence of gastrin. Nature (Lond.), 207, 1356-1359.
Rowlands, E. N., and Wolff, H. S. (1960). Telemetering from the digestive tract. Brit. Comm. Electron., 7, 598-601.

Rune, S. J. (1966). Comparison of the rates of gastric acid secretion in man after ingestion of food and after maximal stimulation with histamine. Gut, 7, 344-350.

Schapiro, H., and Woodward, E. R. (1955). Inhibition of gastric motility by acid in the duodenum. J. appl. Physiol., 8, 121-127.

Singleton, J. W., Kern, F., Jr., and Waddell, W. R. (1965). Diarrhoea and pancreatic islet cell tumor. Gastroenterology, 49, 197-208.

Smith, A. N., and Hogg, D. (1966). Effect of gastrin II on the motility of the gastrointestinal tract. Lancet, 1, 403-404.

Summerskill, W. H. J. (1959). Malabsorption and jejunal ulceration due to gastric hypersecretion with pancreatic islet.cell hyperplasia. Ibid., 1, 120-123.

Wormsley, K. G., and Grossman, M. I. (1965). Maximal histalog test in control subjects and patients with peptic ulcer. Gut, 6, 427-435.

_- Mahoney, M. P., and Ng, M. (1966). Effects of a gastrin-like pentapeptide (I.C.I. 50,123) on stomach and pancreas. Lancet, 1, 993-996. 